\title{
LIX. On purifying coal-gas, and increasing the quantity produced from a given weight of coals
}

\author{
Mr. G. Lowe
}

To cite this article: Mr. G. Lowe (1818) LIX. On purifying coal-gas, and increasing the quantity produced from a given weight of coals, Philosophical Magazine Series 1, 52:247, 371-373, DOI: $10.1080 / 14786441808652066$

To link to this article: http://dx.doi.org/10.1080/14786441808652066

册 Published online: 27 Jul 2009.

Submit your article to this journal

Џ Article views: 2

Q View related articles $₫$ 
Might not the tedious process of forming the red oxide of mercury be considerably accelerated, by sending a minutely divided stream of air through it in the same manner from a gasometer of condensation? The same holds good with cupellation, and many other chemical processes.

I would recommend to those who are near a gas establishment, to provide themselves with what may be called a gas furnace. It consists of a thin metallic tube $d$, open at the top but closed at both ends, and bent in the form of a cornu ammonis, with about half an inch distance between the whirls to admit a free access of air from beneath. By this means a degree of heat may he produced, which will combine the power of a table furnace with the uniformity and elegance of an Argand lamp, but without the incumbrance or the trouble of either.

I ain

Your humble servant,

G. D.

LIX. On purifying Coal-Gas, and increasing the Quantity produced from a given Weight of Coais. By Mr. G. Lowe.

\section{To $M r$. Tilloch.}

$S_{\text {Ir, }}-\mathbf{T}_{\mathrm{HE}}$ Number for this month of your excellent Magazine having just arrived, I have read with pleasure Mr. Parker's letter on the subject of purifying coal-gas. At a time like the present, when the sources of real light are so highly taxed, and the materials of artificial light so dearly bought, we camnot be surprised that so many should be turning their attention to this excellent and too long neglected medium, in order to render the procuring of it so cheap that the lumble cottage may not be debarred of its benefits; and so pure, that even the palace mav show forth its excellence. It is under this consideration that I feel less surprise at finding my own plans of purifying gas anticipated in the experience of Mr. Parker: with a difference only in the method of application ; for although we both agree in passing the gas through a high temperature, yet the very different methods which we have hit upon of sopresenting it, will fully satisfy us both as to our originality of the same idea. Mr. Parker uses three ignited tubes without any other oxidizeable surface. I use only one, into which various oxidizeable surfaces are introduced. The experiments which led me to this method were made in March last, in which experiments the hope of so construcing a stove as to give off both light and heat, of simplicity of construction and with purity of gas, was the desirable object which stimulated my proceedings; in the gaining of which, I am happy to say, I fully succeeded. 
To give your readers a perfect idea of my stove, which might not unaptly he called a Thermophotogen, would be impossible without a plate, for which there is not now time, as I could wish this notice of $M r$. P'arker's paper to appear in your next number. - Suffice it to say, that the body of the stove is an upright cylinder of cast iron, standing four feet high, rather conical, being ten inches diameter insicle at the top, and twelve inches at the bottom. For the sake of portableness, and to ensure against expansion, it is divided into three separate pieces. First, an ashpit eight inches deep, having a door in its side to regulate the draught : second, the part one foot eight inches high containing the door through which fuel is introduced, and opposite to which is an aperture to receive an iron cylinder or gun-barrel: and thirdly, the part in which at its side is placed the que. The parts fit in proper order one upon another, having the joints covered by a small plinth; the top is open, through which is placed a cylindrical retort of two feet six inches long, and seven inches diameter, its fanch forming a top to the stove and covering the flue, which the difference of the diameter of the retort and that of the interior of the stove allows. It is evident, that if the body of the stove be now inclosed with a light sheet iron carcase, leaving a hot air flue all round except at the doors, the heat given off by the stove may be conveyed into apartments; at the same time that its internal heat is liberating the gas in the retort. The cap of the retort is on the simplest construction, like that of the common culinary digester, only fitted with a plug and socket by which the gas is conveyed through a cylinder containing iron turnings, \&c. after which it passes through lime-water or not at pleasure. This method requires very little fuel, serves two purposes, and makes very pure gas. The scale upon which the foregoing apparatus is constructed may be said to be but small, though amply large enough for the majority of families; yet it proves sufficiently that its principle is calculated to obtain every advantage reasonably to be hoped for. - First, a very great increase of gas is obtained from a given quantity of coal, in comparison to the old method, in which the essential oil, the tar, and the water of crystallization are all condensed prior to washing: but by passing through iron turnings, or any oxidizeable surfaces, the two first are nearly all converted into gas, and come even with the hydrogen of the latter, which has been liberated at the experse of the iron turnings. - It is evident, the great increase arises infinitely more from the decomposition of the water than of the tar, which I am afraid Mr. Parker's tubes alone after a short time will fail to do. Secondly, the nuisance creating sulphuretted lyydrogen is perfectly deconposed, as well as the carbonic acid and ammoniacal gases. And last, though not least 
in consideration, it materially lessens the expense in setting up, as well as in wear and tear, for it does not require the retort to be heated any thing near so hot. We must all agree with Mr. Parker, that the subject of these decompositions is worthy a strict examination, and which indeed they have had in their uncombined state by many of the first chemists of the day, but not in combination-as in coal-gas. That the sulphuretted hydrogen may be decomposed by the mere matter of heat, and converted into carburetted hydrogen by passing it over ignited charcoal, is well known ; and that the carbonic acid is converted into carbonic oxide by giving a portion of its oxygen to the iron, one may suppose ; but how the ammoniacal gas, which, according to Thenard, is decomposed without the iron receiving any addition, or the volume of the gas being in the least altered, remains to be explained. In a future Number of your Magazine, if you should think it worthy a place, I perhaps shall be able to send you an account of the same principle of purifying, still further simplified, as applicable to horizontal retorts; in which the tube containing the iron turnings, scraps of tin, charcoal, \&c. is placed within the body of the retort. We are now setting one up, but it is not in sufficient progress to describe. Pardon me the length of this hasty letter, and believe me

Derby, Nov. 14, 1818.

Your well wisher,

G. Lowe.

\section{Notices respecting New Books.}

Is spring last Dr. Watt of Glasgow published a Prospectus, accompanied with a specimen, of a work to be entitled "Bibliotheca Britannica: or a General Index to the Literature of Great Britain and Ireland, ancient and modern, with such Foreign Works as have been translated into English, or printed in the British Dominions : including also a copious selection from the writings of the most celebrated authors of all ages and nations. In Two Parts. In the first, the authors are arraiged alphabetically, and of each, as far as possible, a short biographical notice is given; to which is subjoined a correct list of his works, their various editions, sizes, prices, $8 \mathrm{c}$., and in many instances the character of the work. In the second, the subjects are arrangerl al phabetically; and, under each, the works, and principal parts of works, treating of that subject are arranged in chronological order. This part also includes all the anonymous works which have appeared in this country, inserted according to their respective subjects and dates." A first part of this work is now in the press, and will be published in February. This, consisting of 35 sheets, or 280 pages, is calculated to be about $\mathrm{A}$ a 3 one 